MEDICINE AND THE LAW

\title{
Must doctors disclose their fees before treatment?
}

D J McQuoid-Mason

David McQuoid-Mason is Professor of Law at the Centre for Socio-Legal Studies, University of KwaZulu-Natal, Durban, South Africa, and publishes and teaches in medical law.

Corresponding author: D J McQuoid-Mason (mcquoidm@ukzn.ac.za)

The bioethical principles of patient autonomy, beneficence, non-maleficence and justice or fairness require doctors to disclose their fees before treating patients. The provisions regarding disclosures about fees in the Health Professions Act and National Health Act are in conflict. Those in the National Health Act are likely to be applied by the courts to impose a legal duty on healthcare practitioners to disclose their fees before treating patients. This is because the National Health Act is consistent with the access to healthcare provision in the Constitution, as the nature of the access is often determined by the patient's ability to afford the treatment. Given the unequal bargaining power between doctors and patients, very few patients may ask doctors what their fees are before being treated. It is feasible for doctors to provide such information, or an estimate, and ethically and legally they have a duty to do so.

S Afr Med J 2015;105(2):96-97. DOI:10.7196/SAMJ.9096

口果回

Whether there is an ethical and legal duty on doctors to inform their patients of their fees before treatment depends on the ethical principles applied to healthcare practitioners and interpretation of the Health Professions Act $^{[1]}$ and the National Health Act. ${ }^{[2]}$ The courts must resolve the conflict where statutes dealing with the same topic differ, e.g. with regard to healthcare practitioners providing information about their fees. This begs the question whether it is feasible for doctors to implement such ethical and legal duties.

Bioethical principles require that doctors respect their patients' autonomy and apply the principles of beneficence, non-maleficence and fairness or justice. ${ }^{[3]}$ These can also be used to justify whether doctors should inform patients about their fees.

Patient autonomy ${ }^{[4]}$ concerning payment of fees requires doctors to respect the freedom of patients to decide what form of payment they wish to use or whether they can afford it. Patients are entitled to know the costs of their treatment because these affect: $(i)$ their future available medical aid cover; (ii) how much they will need to co-pay when a doctor has contracted out of medical scheme rates; (iii) how much it will cost should they pay the doctor directly; and (iv) whether they should approach the public sector.

The principles of beneficence ${ }^{[5]}$ and non-maleficence ${ }^{[6]}$ also support the principle of patient autonomy concerning information about fees. Patients benefit by knowing how much of their medical aid or cash reserves will be used by the fees for the treatment or procedure. Some patients may then inform their doctor(s) that they cannot afford their services because they are not members of a medical scheme, they have consulted a doctor who has contracted out of medical scheme tariffs, or they are financially unable to pay for the consultation directly. In emergencies the principles of beneficence and non-maleficence apply, regardless of the patient's ability to pay - the doctor must stabilise the patient before referral, as the Constitution states that nobody may be refused emergency medical treatment. ${ }^{[7]}$ In non-emergency cases, the doctor is still required to do good for the patient, and avoid harm, e.g. by referral to the public sector or, if the doctor has contracted out of medical scheme rates, to a colleague who has not contracted out.

The principle of fairness or justice ${ }^{[8]}$ also requires doctors to inform patients how much their medical treatment or procedure is going to cost when done in their rooms, as such costs impact on the patient's medical scheme or private purse. Doctors, however, cannot be expected to inform patients of fees to be charged by other healthcare professionals when they refer them. However, they may be able to advise a patient that the other practitioner charges medical scheme tariffs, or has contracted out of them, or to provide an estimate for the costs of tests or procedures. The referring doctor should warn patients that the other practitioner or testing agency will also charge a fee. Sometimes patients do not understand this, and complain to the Health Professions Council of South Africa that they were not told by the referring doctor that there would be additional costs.

\section{The Health Professions Act and National Health Act}

The Health Professions Act states that, unless it is impossible, practitioners shall inform their patients (or the person responsible for them) of the fee to be charged before providing professional services. ${ }^{[1]}$ However, this is qualified by stating that information about fees must be given when requested by the person concerned, or when such fee exceeds that usually charged. ${ }^{[1]}$ In the latter case, the doctor must inform the patient or responsible person of 'the usual fee. ${ }^{[1]}$ The Act does not define 'usual fee', but presumably means 'the fees used by a professional board as the norm. ${ }^{[9]}$

Except where the doctor charges a higher than usual fee, the onus of requesting information is placed on the patient. This is in conflict with the National Health Act, which requires the provider to disclose the costs to the patient. ${ }^{[2]}$

The National Health Act requires a healthcare provider to inform 'users' (patients and persons acting on their behalf) not only about 'the range of diagnostic procedures and treatment options generally available' but also about 'the benefits, risks, costs [my italics] and consequences associated with each option. ${ }^{[2]}$ This statement is not qualified by stating that such information must be given if requested by the patient. ${ }^{[1]}$ The obligation on healthcare providers to mention their costs is mandatory - '[every] health care provider must inform [my italics] a user of ... the costs of the diagnostic procedure and treatment options ${ }^{[1]}$ - unlike the Health Professions Act, ${ }^{[2]}$ which implies that it is discretionary except where the patient requests them. The courts must decide whether the provisions in the National Health Act supersede those in the Health Professions Act. 


\section{Resolving the conflict between the Acts}

When interpreting a general statute, the courts presume that, if there is a conflict between the provisions in an earlier general statute and a later general statute dealing with the same topic, the provisions in the later statute revoke the earlier statute. This is applied where the provisions in the later statute are inconsistent and irreconcilable with an earlier statute. ${ }^{[9]}$ However, the courts invoke this presumption sparingly because 'it is also presumed that a statutory provision is not aimed at altering or abrogating the existing law more than necessary. ${ }^{[10]}$ An alteration or abrogation must also be consistent with the Constitution. ${ }^{[7]}$

There is a conflict between the provision in the Health Professions Act that information regarding fees must be given by a healthcare practitioner ' when so requested' [my italics], ${ }^{[1]}$ and the provision in the National Health Act which states that the health care provider ' $m u s t$ inform' [my italics] the user of 'the costs associated with each option' regarding the 'diagnostic procedures and treatment options. ${ }^{[2]}$ The National Health Act provides 'a framework for a structured uniform health system ... taking into account the obligations imposed by the Constitution and other laws.' ${ }^{[11]}$

The Constitution provides that everyone has the right of access to healthcare services. ${ }^{[12]}$

Whether or not patients can exercise their constitutional right of access to healthcare may depend on their ability to afford the practitioner's services by paying the practitioner directly, relying on their medical scheme, or approaching the public sector. Patients may only be able to make this choice after being informed about the likely fees.

The constitutional right of access to information ${ }^{[13]}$ would be satisfied if doctors made information about fees available on request from their patients where an equal power relationship exists. However, given the generally unequal power relationship between doctors and their patients, particularly when patients are ill and vulnerable, many may not make such requests, thus undermining the patient's right of access to healthcare. The doctor's duty to disclose the costs of procedures and treatment as required by the National Health $\mathrm{Act}^{[1]}$ therefore concurs with the constitutional ${ }^{[12]}$ right of access to healthcare, and should be adhered to by healthcare practitioners.

Some provisions in the Health Professions Act regarding fees charged by healthcare professionals ${ }^{[1]}$ were amended after the National Health Act came into effect. However, the National Health Act provision $^{[2]}$ is more consistent with the spirit of the Constitution ${ }^{[12]}$ than the unchanged provision in the Health Professions $\mathrm{Act}^{[1]}$ that places the onus on patients to request information about the practitioner's fees.

\section{Is it feasible for doctors to inform patients about their treatment cost?}

Some practitioners argue that it is not feasible always to advise their patients beforehand regarding the cost of their treatment. However, it must be possible to specify what their consultation, procedures, hourly fees, etc. are, or to provide an approximate fee.

It is sometimes said that doctors cannot estimate how much the scheme will cover for a medical scheme member, because this is a matter between the patient and their medical scheme and depends on their contract. ${ }^{[14]}$ However, when obtaining preauthorisation for medical or surgical procedures or hospital stays, practitioners should be able to ascertain whether the medical scheme will cover these, and advise their patients accordingly. Similarly, when patients are referred to another practitioner they must be warned that the other practitioner will charge a fee additional to that of the referring doctor. Doctors can also sometimes give a reasonably accurate estimate of what the procedure or test is likely to cost, e.g. radiology or pathology tests.

In any event, where doctors charge rates above those 'usually charged for such services', e.g. when they have contracted out of medical scheme rates, the Health Professions Act legally requires them to inform their patients of their fee, and the fee that would usually be charged. ${ }^{[1]}$ If such doctors must inform their patients of their intended fee and the 'usual rates', it seems reasonable for doctors who charge the 'usual rates' to do likewise, or to provide an estimate.

In the USA, patients are increasingly likely to demand disclosure of the cost of care, and the websites of organisations such as Clear Health Care Beta ${ }^{[15]}$ and Pricing Healthcare ${ }^{[16]}$ have databases of the fees charged by different doctors to enable patients to estimate their healthcare costs in advance of consultations. ${ }^{[14]}$

\footnotetext{
1. Section 53(1) of the Health Professions Act No. 56 of 1974. www.hpcsa.co.za/.../legislations/acts/ health_professions-ct-56-1974.pdf (accessed 17 December 2014).

2. Section 6(1)(b) and (c) of the National Health Act No. 61 of 2003. (www.lawsofsouthafrica.up.ac.za/... health/national-health-act-61-of-2003/ (accessed 17 December 2014).

3. Beauchamp TL, Childress JF. Principles of Biomedical Ethics. 3rd ed. Oxford: Oxford University Press, 1994:67-113 (autonomy), 194-249 (beneficence), 120-184 (non-maleficence), 256-302 (justice).

4. Beauchamp TL, Childress JF. Principles of Biomedical Ethics. 3rd ed. Oxford: Oxford University Press, 1994:67-113.

. Beauchamp TL, Childress JF. Principles of Biomedical Ethics. 3rd ed. Oxford: Oxford University Press, 1994:194-249.

6. Beauchamp TL, Childress JF. Principles of Biomedical Ethics. 3rd ed. Oxford: Oxford University Press, 1994:120-184.

7. Section 27(3) of the Constitution of the Republic of South Africa, 1996. www.justice.gov.za/legislation/ constitution/constitution.htm (accessed 17 December 2014)

8. Beauchamp TL, Childress JF. Principles of Biomedical Ethics. 3rd ed. Oxford: Oxford University Press, 1994:256-302.

9. Section 53(3)(d) of the Health Professions Act No. 56 of 1974. www.hpcsa.co.za/.../legislations/acts/ health_professions-ct-56-1974.pdf (accessed 17 December 2014).

10. Du Plessis LM. Statute law and interpretation. In: Joubert WA, Faris JA, eds. The Law of South Africa. Vol 25, part 1. 2nd ed. Durban: LexisNexis, 2011.

11. Preamble to the National Health Act No. 61 of 2003 .

12. Section 27(1)(a) of the Constitution of the Republic of South Africa, 1996.

13. Section 32(1) of the Constitution of the Republic of South Africa, 1996

14. Ubel P. Doctors must discuss the cost of care with their patients. Policy July 10 2014. http://www. kevinmd.com/blog/2014/07/doctors-must-discuss-cost-care-patients.html (accessed 28 October 2014). 15. Clear Health Costs Beta. http://www.clearhealthcosts.com (accessed 28 October 2014).

16. Pricing Healthcare. http://www.pricinghealthcare.com (accessed 28 October 2014).
} 